\title{
Commentary: Dealer's choice!
}

\author{
Frank A. Baciewicz, Jr, MD
}

\footnotetext{
From the Division of Cardiothoracic Surgery and Michael and Marian Ilitch Department of Surgery, Wayne State University School of Medicine, Detroit, Mich.

Disclosures: Author has nothing to disclose with regard to commercial support.

Received for publication Aug 6, 2019; revisions received Aug 6, 2019; accepted for publication Aug 7, 2019; available ahead of print Oct 23, 2019.

Address for reprints: Frank A. Baciewicz, Jr, MD, Department of Cardiothoracic Surgery, Michael and Marian Ilitch Department of Surgery, Wayne State University School of Medicine, Harper Hospital, 3990 John R St, Detroit, MI 4820 (E-mail: fbaciewi@dmc.org).

J Thorac Cardiovasc Surg 2020;159:2200-1

0022-5223/ $\$ 36.00$

Copyright $(2019$ Published by Elsevier Inc. on behalf of The American Association for Thoracic Surgery https://doi.org/10.1016/j.jtcvs.2019.08.066
}

The isolated left vertebral artery (ILVA) has its origin directly off the aorta, and is the second most common (after bovine arch) aortic arch variant, occurring in $2 \%$ to $4 \%$ of patients. ${ }^{1,2}$ In their article in this issue of the Journal, "Transposition of the Left Vertebral Artery During Endovascular Stent-Graft Repair of the Aortic Arch," Piffaretti and colleagues ${ }^{3}$ report their experience with transposition of the ILVA during stent-graft repair of the aortic arch and descending thoracic aorta. They achieved successful outcomes without neurologic sequelae in all cases. However, a question remains-should the ILVA be rerouted during endovascular stent repair, or can this technically demanding step be avoided (dealer's choice)? This is a similar dilemma faced during zone 2 thoracic endovascular aortic repair (TEVAR) with the usual origin of the left vertebral artery (LVA).

When a zone 2 TEVAR graft covers the left subclavian artery (LSA), the LVA flow is altered. In a meta-analysis, Dunning and colleagues ${ }^{4}$ reviewed 498 cases of covered LSA with only a $2.6 \%$ stroke rate and a $1.8 \%$ paraplegia or paraparesis rate. They concluded that in emergency cases, the LSA could be occluded. In elective situations, they advocated assessing the status of the carotid arteries, the right vertebral artery, and the circle of Willis with ultrasonographic, computed tomographic, or magnetic resonance imaging scan before deciding on LSA coverage with or without LVA revascularization.

Woo and colleagues ${ }^{5}$ described 49 patients with LSA stent coverage without neurologic sequelae. His group used selective subclavian transposition or LSA to carotid artery bypass (LSCB) with ligation proximal to the LVA in cases in which the right vertebral or basilar artery had abnormal anatomy.

In the experience of Piffaretti and colleagues, ${ }^{3}$ ILVA transposition was a rarely employed procedure as they noted an ILVA in 9 of 279 patients from 2007 to 2018. Only 6 of these 9 patients required transposition, because in 1 case the ILVA was occluded, 1 patient needed repair of a saccular aneurysm off the inferior transverse arch,

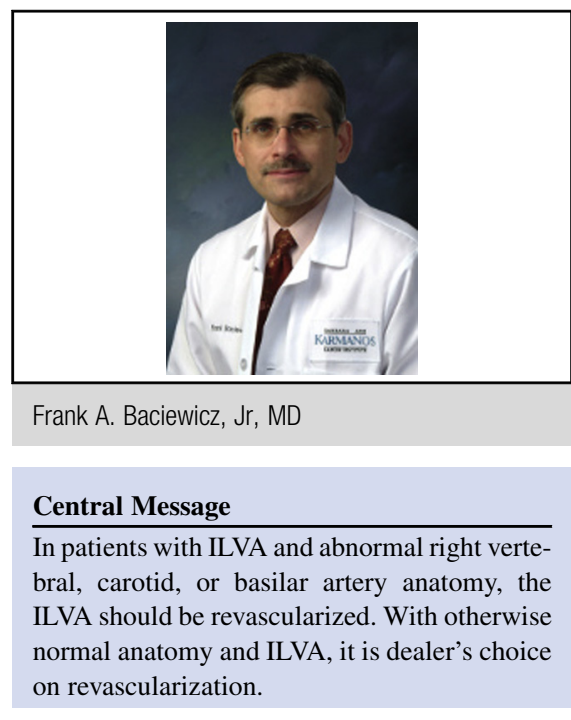

See Article page 2189.

and 1 patient required a descending thoracic stent without LSA coverage. All 6 of the patients who underwent transposition of the ILVA had long-term patency of their bypass and no neurologic complications, and they averaged 4 days of hospitalization for stent-graft procedures and a 12-day hospital course for the open procedures. Piffaretti and colleagues $^{3}$ mentioned that 1 patient had a residual Horner syndrome, but there were no lymphatic complications, no reinterventions, and no revisions. This achievement is impressive, because ILVA transposition can be difficult, especially in a patient with a short, deep neck. Table 3 in the article of Piffaretti and colleagues ${ }^{3}$ is confusing, because 6 patients underwent ILVA transposition-2 after TEVAR only and 2 at the time of arch repair (left carotid artery/LVA as a common graft)—so there should be 2 patients with open arch repair and LSCB and ILVA transposition. However, the article's Table 3 shows only 3 of the 6 patients with LSCB and ILVA transposition.

What is the strategy of Piffaretti and colleagues ${ }^{3}$ for zone 2 TEVAR coverage of the LSA in patients with normal vertebral artery, carotid arteries, and Circle of Willis? From this publication, I assume that they use LSCB and some method of LVA revascularization. What is their game plan with the new generation of stent grafts, which have a limb entering the subclavian with the main graft covering the LSA? With normal LVA anatomy, the LVA flow may be compromised by the single limb, and with variant ILVA, the ILVA will be covered by the new stent. 
Kamman and associates ${ }^{6}$ investigated carotid and vertebral arterial flows by Doppler in 74 patients who underwent either transposition of LSA to the left common carotid artery $(n=4)$ or LSCB $(n=70)$ at the time of zone 2 TEVAR. LVA flow decreased in $22 \%$ of the patients, and LVA flow was retrograde in $8 \%$. Peak systolic velocity in the LVA decreased an average of $55 \pm 22.0 \mathrm{~cm} / \mathrm{s}$ to $35.9 \pm 26.0 \mathrm{~cm} / \mathrm{s}$ with LSA revascularization. Peak systolic velocity did not change in the left carotid artery after LSCB. Even with $100 \%$ graft or transposition patency, 5 patients had strokes $(6.9 \%)$, with 3 strokes in the posterior circulation, 2 strokes in the left hemisphere, and 3 in both hemispheres. Because Kamman and associates ${ }^{6}$ demonstrated left LVA flow decrease with LSA revascularization during zone 2 TEVAR, one can conclude that LVA flow is likely further compromised without LSA revascularization. LVA revascularization should be a consideration with LSA coverage, even though the probability of stroke is low.

If the right vertebral artery is abnormal and the left or right carotid artery is stenotic, then LSA or LVA revascularization or LSA transposition should be performed, because the risk for devastating neurologic complications increases. Patients undergoing zone 2 TEVAR with infrarenal abdominal aortic grafts or stents are at increased risk for paraplegia and are candidates for revascularization of the LSA or LVA. Patent left internal thoracic artery to left anterior descending coronary artery graft is another situation in which LSA flow must be preserved.
Except for specific clinical scenarios, the decision for ILVA and LVA revascularization still appears to be dealer's choice!

Postscript: The invitation to comment on the article of Piffaretti and colleagues ${ }^{3}$ afforded an opportunity to review the clinical expertise of Dr Ramon Berguer, former Chairman of Vascular Surgery at Wayne State University, who published one of the earliest and largest series of vertebral artery reconstructions. ${ }^{7}$

\section{References}

1. Popieluszko P, Henry BM, Sanna B, Hsieh WC, Saganiak K, Pękala PA, et al. A systematic review and meta-analysis of variations in branching patterns of the adult aortic arch. J Vasc Surg. 2018;68:298-306.e10.

2. Lazaridis N, Piagkou M, Loukas M, Piperaki ET, Totlis T, Noussios G, et al. A systematic classification of the vertebral artery variable origin: clinical and surgical implications. Surg Radiol Anat. 2018;40:779-97.

3. Piffaretti G, Gelpi G, Tadiello M, Ferrarese S, Socrate AM, Tozzi M, et al. Transposition of the left vertebral artery during endovascular stent-graft repair of the aortic arch. J Thorac Cardiovasc Surg. 2020;159:2189-98.e1.

4. Dunning J, Martin JE, Shennib H, Cheng DC. Is it safe to cover the left subclavian artery when placing an endovascular stent in the descending thoracic aorta? Interact Cardiovasc Thorac Surg. 2008;7:690-7.

5. Woo EY, Bavaria JE, Pochettino A, Gleason TG, Woo YJ, Velazquez OC, et al Techniques for preserving vertebral artery perfusion during thoracic aortic stent grafting requiring aortic arch landing. Vasc Endovascular Surg. 2006;40:367-73.

6. Kamman AV, Eliason JL, Williams DM, Yang B, Moll FL, Trimarchi S, et al Impact of left subclavian artery revascularization before thoracic endovascular aortic repair on postoperative cerebrovascular hemodynamics. Ann Vasc Surg. 2018;46:307-13.

7. Berguer R, Morasch MD, Kline RA. A review of 100 consecutive reconstructions of the distal vertebral artery for embolic and hemodynamic disease. J Vasc Surg. 1998;27:852-9. 